\title{
Enhanced coagulation for high alkalinity and micro-polluted water: The third way through coagulant optimization
}

\author{
Mingquan Yan ${ }^{a, b}$, Dongsheng Wang, ${ }^{b, *}$, Jiuhui $\mathrm{Qu}^{b}$, Jinren $\mathrm{Ni}^{a}$, Christopher W.K. Chow \\ ${ }^{a}$ Department of Environmental Engineering, College of Environmental Science and Technology, \\ The Key Laboratory of Water and Sediment Sciences, MOE, Peking University, Beijing 100871, China \\ ${ }^{\mathrm{b}}$ State Key Laboratory of Environmental Aquatic Chemistry, Research Center for Eco-Environmental Sciences, CAS, \\ P.O. Box 2871, Beijing 100085, China \\ ${ }^{\mathrm{C} C R C}$ for Water Quality and Treatment, Australian Water Quality Centre, SA Water, Private Mail Bag 3, Salisbury, \\ South Australia 5108, Australia
}

\section{A R T I C L E I N F O}

Article history:

Received 23 August 2007

Received in revised form

1 December 2007

Accepted 6 December 2007

Available online 15 December 2007

Keywords:

Alkalinity

Coagulant aid

Composite polyaluminum chloride

(HPAC)

Enhanced coagulation

Natural organic matter (NOM)

\begin{abstract}
A B S T R A C T
Conventional coagulation is not an effective treatment option to remove natural organic matter (NOM) in water with high alkalinity/pH. For this type of water, enhanced coagulation is currently proposed as one of the available treatment options and is implemented by acidifying the raw water and applying increased doses of hydrolyzing coagulants. Both of these methods have some disadvantages such as increasing the corrosive tendency of water and increasing cost of treatment. In this paper, an improved version of enhanced coagulation through coagulant optimization to treat this kind of water is demonstrated. A novel coagulant, a composite polyaluminum chloride (HPAC), was developed with both the advantages of polyaluminum chloride (PACl) and the additive coagulant aids: PACl contains significant amounts of highly charged and stable polynuclear aluminum hydrolysis products, which is less affected by the $\mathrm{pH}$ of the raw water than traditional coagulants (alum and ferric salts); the additives can enhance both the charge neutralization and bridging abilities of PACl. HPAC exhibited $30 \%$ more efficiency than alum and ferric salts in dissolved organic carbon (DOC) removal and was very effective in turbidity removal. This result was confirmed by pilot-scale testing, where particles and organic matter were removed synergistically with HPAC as coagulant by sequential water treatment steps including pre-ozonation, coagulation, flotation and sand filtration.
\end{abstract}

(c) 2007 Elsevier Ltd. All rights reserved.

\section{Introduction}

Natural organic matter (NOM) can cause taste, odor and color problems in potable water, and bacterial regrowth in distribution systems. More importantly, NOM is a precursor for disinfection by-products, such as trihalomethanes (THMs) and haloaetic acids (HAAs), which are found to be carcino- gens (USEPA, 1998). Recently, the US Environmental Protection Agency (USEPA) has established more stringent maximum contaminant levels of 80 and $60 \mu \mathrm{g} / \mathrm{L}$ for THMs and HAAs, respectively, for finished drinking water. Effective removal of NOM is one of the major challenges for the modern drinking water treatment industry. Enhanced coagulation has been proposed as the best available technology for

\footnotetext{
*Corresponding author. Tel.: +8610 62849138; fax: +861062923541.

E-mail addresses: Yankingcn@yahoo.com (M. Yan), Sunwds@yahoo.com (D. Wang). 0043-1354/\$ - see front matter ๔ 2007 Elsevier Ltd. All rights reserved.
} doi:10.1016/j.watres.2007.12.006 
NOM removal, and the regulation for percentage removal of NOM expressed in total organic carbon (TOC) was set up based on raw water quality. Application of the regulation (in the US) involves two steps: Step 1 defines the required removal percentage of TOC according to the raw water TOC and alkalinity levels. Step 2 provides an alternative performance criterion, when it is technically not feasible for treatment plants to meet Step 1 TOC removal requirements. The alternative TOC removal target is determined by jar testing to achieve a required TOC removal (more than $0.3 \mathrm{mg} / \mathrm{L}$ TOC removal per increasing $10 \mathrm{mg} / \mathrm{L}$ coagulant) with the combination of depressing the coagulation/flocculation $\mathrm{pH}$ to a lower value (USEPA, 1998).

For the non-prehydrolyzed coagulants, alum and ferric salts, maximum NOM removal occurs under slightly acidic conditions $(\mathrm{pH}<6.0)$. However, for high-alkalinity waters, the high-pH conditions provide excess $\mathrm{OH}^{-}$for metal hydrolyzation and consequent formation of hydroxide precipitate, which is not as efficient as polymeric metal cations for organic matter (OM) removal. Enhanced coagulation for highalkalinity water is generally performed in two ways: acidifying the raw water or applying increased dosage of coagulants (Crozes et al., 1995; USEPA, 1998). Both of these methods have some disadvantages such as increasing the corrosive tendency of the water and treatment costs (Carlson et al., 2000).

Some source waters are seriously polluted by synthetic organic contaminants (SOCs) from industrial discharge (Yan et al., 2006). Some of these SOCs are low molecular weight and hydrophilic compounds with low specific UV absorbance (SUVA) values, which shared the character of difficult to remove by conventional treatment process, especially by coagulation (Edzwald, 1993). For water with SOC present, the removal efficiency of OM by coagulation is low even at high dosage and optimal $\mathrm{pH}$ region with traditional metal coagulants (Yan et al., 2006). Therefore, exploring new options to treat organic polluted source water with high alkalinity is important. This paper reports an optimization study of coagulants and the application of a composite coagulant to improve the efficiency of NOM removal.

\section{Materials and methods}

\subsection{Materials}

The two coagulants, aluminum chloride $\left(\mathrm{AlCl}_{3}\right)$ and ferric chloride $\left(\mathrm{FeCl}_{3}\right)$, used in bench-scale tests were of reagent grade (Chemical Regent Co., Tianjin, China). $\mathrm{FeCl}_{3}$ (with $\mathrm{Fe}_{2} \mathrm{O}_{3}$ content of $40 \%$ ) used in pilot trials was made by a local company (Tianjin Tianshui Water Cleaning Agent Co., China). Commercial polyaluminum chloride $\left(\mathrm{PACl}_{\mathrm{I}}\right)$ and a novel composite polyaluminum chloride (HPAC) (both with $10 \%$ $\mathrm{Al}_{2} \mathrm{O}_{3}$ content) were produced by a local company (Beijing Wanshui Water Cleaning Agent Co., China) using the technique developed in our laboratory. HPAC was prepared from $\mathrm{PACl}_{\mathrm{I}}$ and other organic and inorganic additives such as active silicates and polydiallyldimethyl ammonium chloride (PDAD$\mathrm{MAC}$ ). The coagulant, $\mathrm{PACl}_{25}$ (with $\mathrm{OH} / \mathrm{Al}$ molar ratio of 2.5), was prepared by a base titration method applied at room temperature (Wang and Tang, 2001). The Al species distribu- tions in the PACls and $\mathrm{AlCl}_{3}$ samples were analyzed by the Ferron Assay (Wang et al., 2004). The Ferron reagent (8-hydroxy-7-iodo-5-quinoline sulfonic acid) was supplied by Sigma, UK. The chemical species of hydrolyzed Al(III) can be classified, based on different reaction rates, into three types: monomeric species $\left(\mathrm{Al}_{\mathrm{a}}\right.$ ) (instantaneous reaction), medium polymer species $\left(\mathrm{Al}_{\mathrm{b}}\right)$ (reaction is less than $120 \mathrm{~min}$ ) and species of sol or gel $\left(\mathrm{Al}_{\mathrm{c}}\right)$ (no reaction). The species distributions of coagulant are shown in Table 1.

Another composite coagulant, polyaluminum-silicatechloride (PASiC) was prepared as follows: slowly adding $10.75 \mathrm{~mL}$ concentrated silica solution (typically $3 \mathrm{M} \mathrm{SiO}_{2}$, commercial grade, Chemical Regent Co., Beijing, China) to $10 \mathrm{~mL} 2 \mathrm{M}$ hydrochloric acid under stirred condition to obtain polysilicate (PSi) solution. The $\mathrm{pH}$ of the PSi solution was between 2.0 and 2.5 at a $\mathrm{SiO}_{2}$ concentration of $1.5 \mathrm{M}$. In the following step, $\mathrm{PACl}_{\mathrm{I}}$ was mixed with fresh PSi solutions with $\mathrm{Al} / \mathrm{Si}$ ratios $\geqslant 5$, to obtain PASiC coagulants (Gao et al., 2002b).

Two kinds of cationic polymers polyacrylamide (PAM) and PDADMAC were selected as coagulant aids, and their molecular weights and charge densities are given in Table 2. Both C1592 and C1596 (Cytec Industries, Inc., USA) are high molecular weight cationic PAM polymers with different charge densities. The charge density of C1592 is relatively high compared with C1596. The PDADMAC (Taicang Floc Company, China) selected was characterized as cationic polymer with lower molecular weight and with much higher charge density as compared with the two PAM polymers. All cationic polymers used were prepared at a concentration of $0.1 \%$ (weight/weight).

Raw water was collected from the Luan River and the Yellow River, located in the North-China region. These are the source waters supplying the Tianjin water treatment plants. The general water quality of the two raw waters is presented in Table 3.

Table 1 - Speciation of coagulant-PACls, monomeric species $\left(\mathrm{Al}_{\mathrm{a}}\right)$, medium polymer species $\left(\mathrm{Al}_{\mathrm{b}}\right)$ and species of sol or gel $\left(\mathrm{Al}_{\mathrm{c}}\right)$

\begin{tabular}{lcccc}
\hline & Basicity & $\mathrm{Al}_{\mathrm{a}}(\%)$ & $\mathrm{Al}_{\mathrm{b}}(\%)$ & $\mathrm{Al}_{\mathrm{c}}(\%)$ \\
\hline $\mathrm{AlCl}_{3}$ & 0 & 91.9 & 8.1 & 0 \\
$\mathrm{PACl}_{\mathrm{I}}^{*}$ & 1.6 & 40.0 & 38.5 & 21.5 \\
$\mathrm{PACl}_{25}{ }^{* *}$ & 2.5 & 5.4 & 77.8 & 16.8 \\
\hline
\end{tabular}

*I means industrial PACl product; **25 means $\mathrm{PACl}$ produced by a base titration method with the target $\mathrm{OH} / \mathrm{Al}$ molar ratio.

Table 2 - The charge density and molecular weight of polyelectrolytes

\begin{tabular}{lcc}
\hline Name & Charge density (\%) & Molecular weight \\
\hline PDADMAC & 100 & Low \\
PAM-C1596 & 40 & High \\
PAM-C1592 & 10 & Very high \\
\hline
\end{tabular}


Table 3 - The average $(N \geqslant 450)$ quality of the raw waters used in this study

\begin{tabular}{lcccc}
\hline & $\begin{array}{c}\text { Turbidity } \\
\text { (NTU) }\end{array}$ & $\mathrm{pH}$ & $\begin{array}{c}\text { Alkalinity } \\
(\mathrm{mg} / \mathrm{L} \text { as } \\
\left.\mathrm{CaCO}_{3}\right)\end{array}$ & $\begin{array}{c}\mathrm{COD}_{\mathrm{Mn}} \\
(\mathrm{mg} / \mathrm{L})\end{array}$ \\
\hline $\begin{array}{lccc}\text { Luan River } \\
\text { Yellow }\end{array}$ & 20.0 & 8.30 & 121.1 & 4.78 \\
River & 8.4 & 8.32 & 156.9 & 4.80 \\
\hline
\end{tabular}

\subsection{Laboratory jar tests}

Jar tests were performed with $1 \mathrm{~L}$ of raw water in $1.4-\mathrm{L}^{2}$ beakers with a sampling port located $3 \mathrm{~cm}$ below the water surface. A programmable jar testing apparatus was used with the following procedures: addition of coagulant followed by $30 \mathrm{~s}$ rapid mixing at $300 \mathrm{rpm}\left(G=172.1 \mathrm{~s}^{-1}\right), 2 \mathrm{~min}$ rapid mixing at $250 \mathrm{rpm}\left(G=134.4 \mathrm{~s}^{-1}\right), 10 \mathrm{~min}$ flocculation at $40 \mathrm{rpm}\left(G=11.3 \mathrm{~s}^{-1}\right)$ and $20 \mathrm{~min}$ settling. Treated water samples were taken after settling for later analyses. Coagulant dosage was measured by a calibrated pipette.

\subsection{Pilot-scale tests}

Treated water samples were collected from a pilot-plant facility of a typical Northern-China water treatment plant, with source water supplied from the Yellow River and the Luan River. The pilot plant has two parallel trains; train one has pre-ozonation, coagulation, dissolved air flotation (DAF) or sedimentation, sand filtration, mid-ozonation, granular activated carbon (GAC) and disinfection. Train two has preozonation, coagulation, DAF, sand filtration, mid-ozonation, GAC and disinfection. The pilot plant was operated with one train using HPAC and the other with $\mathrm{FeCl}_{3}$ as coagulant. During the experiment, the flow rate of each system was controlled at $5 \mathrm{~m}^{3} / \mathrm{h}$. The coagulation process was carried out using the following conditions, rapid mixing ( $t=1 \mathrm{~min}$, $G=756 \mathrm{~s}^{-1}$ ) and two-stage flocculation (in each stage, $t=9 \mathrm{~min}, G=91.5 \mathrm{~s}^{-1}$ ). The surface loading rate of flotation separation pond was $11 \mathrm{~m}^{3} / \mathrm{m}^{2} / \mathrm{h}$, the recycle ratio was $10 \%$ and the saturator pressure was $0.4 \mathrm{MPa}$, residence time was $126 \mathrm{~s}$. The sedimentation pond is equipped with a $60^{\circ}$ inclined pipe and it is $1 \mathrm{~m}$ in length. The depth of the sand filtration bed was $2.7 \mathrm{~m}$, the filtration rate was $7.86 \mathrm{~m} / \mathrm{h}$, and sand with $400 \mathrm{~nm}$ average diameter was used as filter media. The details of the pilot plant have been reported earlier in the literature (Yan, 2006).

\subsection{Analytical methods}

TOC was analyzed using a Phoenix 8000 system (TekmarDohrman Co., USA). Dissolved organic carbon (DOC) was analyzed after filtration through a $0.45 \mu \mathrm{m}$ membrane. $U_{254}$ was measured by a spectrophotometer (UV-vis 8500, China) after filtration through a $0.45 \mu \mathrm{m}$ membrane. SUVA is calculated as $\mathrm{UV}_{254}$ divided by the $\mathrm{mg} / \mathrm{L}$ DOC concentration. Turbidity was measured using a 2100N Turbidimeter (Hach,
USA). Metal elements were analyzed by inductively coupled plasma-atomic emission spectrometry. Total aluminum (Al) and iron ( $\mathrm{Fe}$ ) and dissolved $\mathrm{Al}$ and Fe concentrations were measured before and after sample filtration through $0.45 \mu \mathrm{m}$ membrane, respectively. Prior to total $\mathrm{Al}$ and $\mathrm{Fe}$ analyses, samples were digested by nitric acid. Colloidal $\mathrm{Al}$ and Fe were defined as the difference between total and dissolved $\mathrm{Al}$ or $\mathrm{Fe}$ concentrations (APHA, 1995). The alkalinity and chemical oxygen demand $\left(\mathrm{COD}_{\mathrm{Mn}}\right)$ were measured by standard methods (APHA, 1995). $\mathrm{pH}$ was measured using a pHS-3C $\mathrm{pH}$ meter (Shanghai, China) calibrated daily using $\mathrm{pH}$ buffer solutions. Zeta potential was measured using a Particle MicroElectrophoresis Apparatus (Rank Brothers, Apparatus Mark II, UK). Floc formation (size) during the coagulation/flocculation period was measured using a Galai CIS-1 computerized inspection system (Galai Production Ltd., Darmstadt, Germany), and the procedures reported in Gao et al. (2002a) were used.

\section{Results and discussion}

\subsection{The effect of $\mathrm{pH}$ on coagulation with traditional coagulants}

Fig. 1 shows the optimum NOM/DOC removal conditions for the Yellow River water using traditional coagulants, $\mathrm{FeCl}_{3}$ and $\mathrm{AlCl}_{3}$, which occurred under acidic conditions $\left(\mathrm{FeCl}_{3}\right.$ between 4.0 and 5.5 and $\mathrm{AlCl}_{3}$ between 5.5 and 6.0). The optimum pH range for turbidity removal was at a slightly higher range, 5.6-8.2 for $\mathrm{FeCl}_{3}$ and 6.5-8.2 for $\mathrm{AlCl}_{3}$, as compared with the DOC removal situation. A wider applicable $\mathrm{pH}$ range for $\mathrm{FeCl}_{3}$ was observed when compared with the $\mathrm{pH}$ range of $\mathrm{AlCl}_{3}$. This is because the $\mathrm{pH}$ for $\mathrm{FeCl}_{3}$ hydroxylation and polymerization is lower than that for $\mathrm{AlCl}_{3}$.

As shown in Fig. 2, DOC and turbidity removal correlated well with the hydrolyzing behavior of the coagulants with the minimum solubility of $\mathrm{FeCl}_{3}$ and $\mathrm{AlCl}_{3}$ at $\mathrm{pH} 5.8$ and $\mathrm{pH}$ 6.3,
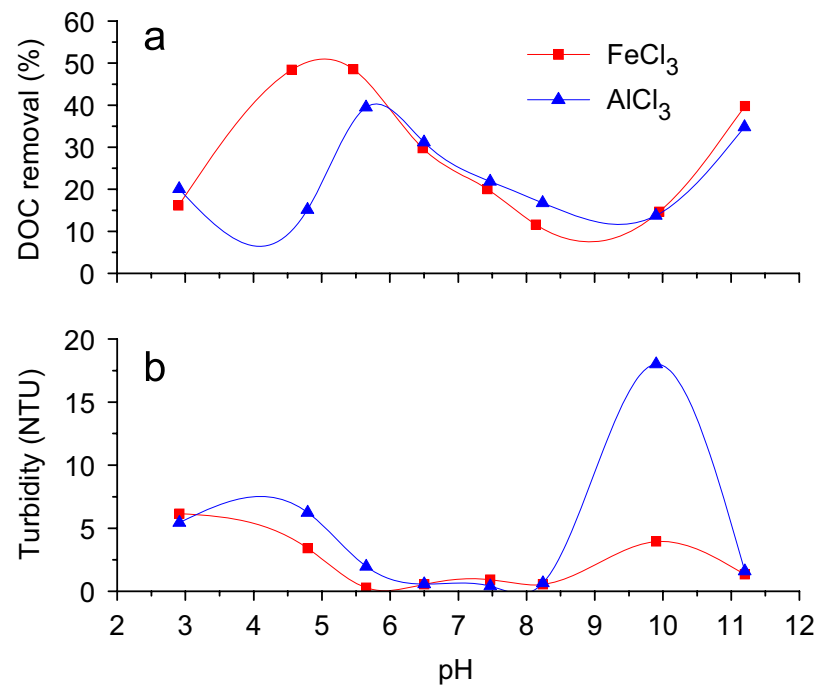

Fig. 1 - Effect of $\mathrm{pH}$ on the coagulation efficiency of $\mathrm{AlCl}_{3}$ and $\mathrm{FeCl}_{3}$ for (a) DOC removal and (b) turbidity removal. 


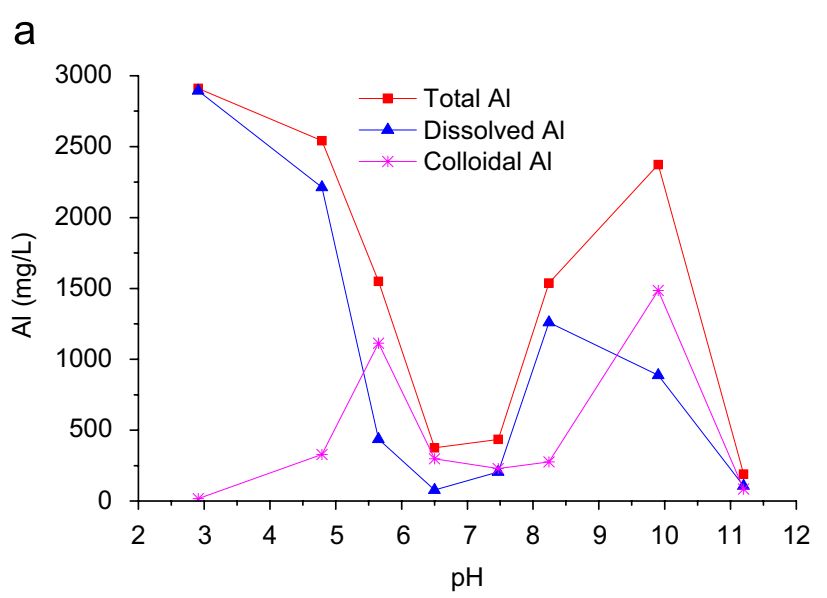

b

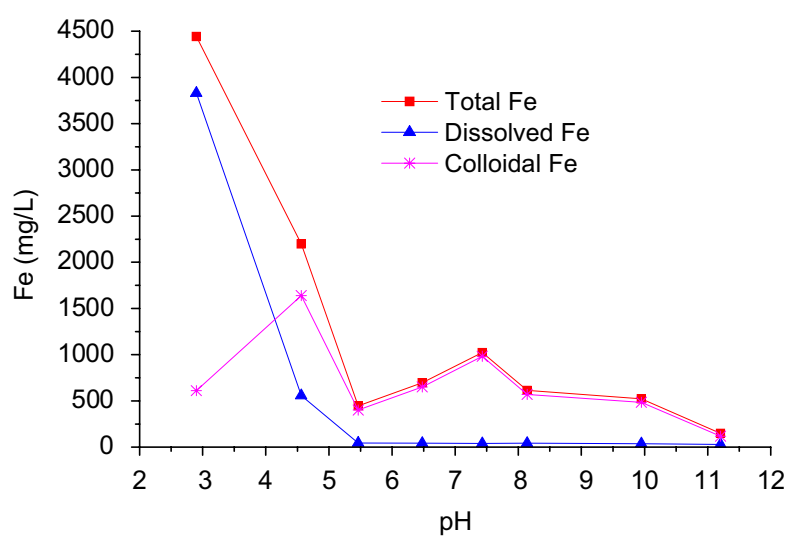

Fig. 2 - Effect of pH on distribution of residual coagulant: (a) residual $\mathrm{Al}$ and (b) residual Fe.

respectively. Turbidity removal is most efficient at $\mathrm{pH}$ slightly higher than that for their minimum solubility $\mathrm{pH}$ for both $\mathrm{FeCl}_{3}$ and $\mathrm{AlCl}_{3}$. However, DOC removal was most efficient at a $\mathrm{pH}$ slightly lower than the $\mathrm{pH}$ of their minimum solubility.

At a $\mathrm{pH}$ higher than the minimum solubility $\mathrm{pH}$, the hydrolysis products of $\mathrm{FeCl}_{3}$ and $\mathrm{AlCl}_{3}$ are high molecular weight polymers or sols, which efficiently remove particles through bridging or sweep flocculation. While at a $\mathrm{pH}$ slightly lower than the minimum solubility $\mathrm{pH}$ of the coagulant, the hydrolysis products of $\mathrm{FeCl}_{3}$ and $\mathrm{AlCl}_{3}$ are mainly medium polymers or monomers, which have a high ability to remove DOC by complexation, adsorption, charge neutralization or co-precipitation. It was observed that the flocs formed at the $\mathrm{pH}$ range would not settle as efficient as those formed at the basic $\mathrm{pH}$ range. For $\mathrm{FeCl}_{3}$ and $\mathrm{AlCl}_{3}$, their metal hydrolysis products complexed with dissolved NOM to a colloidal state at $\mathrm{pH}$ about 5.0 and 5.8, respectively, and the concentrations of colloidal $\mathrm{Al}$ and Fe were high (Fig. 2). Although these colloidal products are rather difficult to be removed by sedimentation alone, it is possible to be removed by $0.45 \mu \mathrm{m}$ filtration.

For both $\mathrm{FeCl}_{3}$ and $\mathrm{AlCl}_{3}$ (Fig. 2), the medium polymeric or monomeric species are the most efficient species for DOC removal, and these kinds of hydrolysis products are produced in an acidic pH condition (Yan et al., 2007a). For water with high alkalinity, the presence of $\mathrm{OH}^{-}$meets the demand of metal hydrolyzation to form sols and precipitates, which is not a favorable condition for effective removal of DOC.

\subsection{Enhanced coagulation of high-alkalinity water with $\mathrm{PACl}$}

Inorganic polymer flocculants (IPFs) have been developed rapidly and it is widely applied, especially in China, Japan, Russia and western Europe (Wang et al., 2004). PACl, one form of IPF, contains high level of charged polymeric Al hydrolysis products. The preformed Al polymers are highly stable, with great stability even after it was dosed into the water (Wang et al., 2004; Yan et al., 2007a). The species distribution of PACl is governed by the degree of pre-hydrolysis, the hydroxideto-Al ratio, which is often referred to the basicity (B) of $\mathrm{PACl}$.

The efficiency of PACls in the treatment of high-alkalinity water was investigated with three PACls with various $B$ values. Results for the Luan River water are shown in Fig. 3. Considering the speciation of the PACls (Table 1), it is indicative that the medium polymer species $\left(\mathrm{Al}_{\mathrm{b}}\right)$ content in

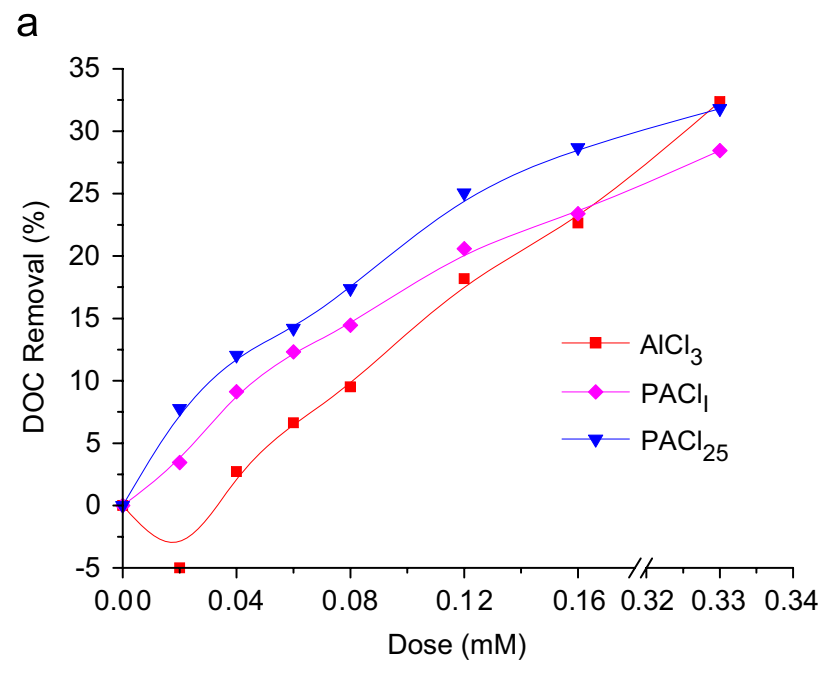

b

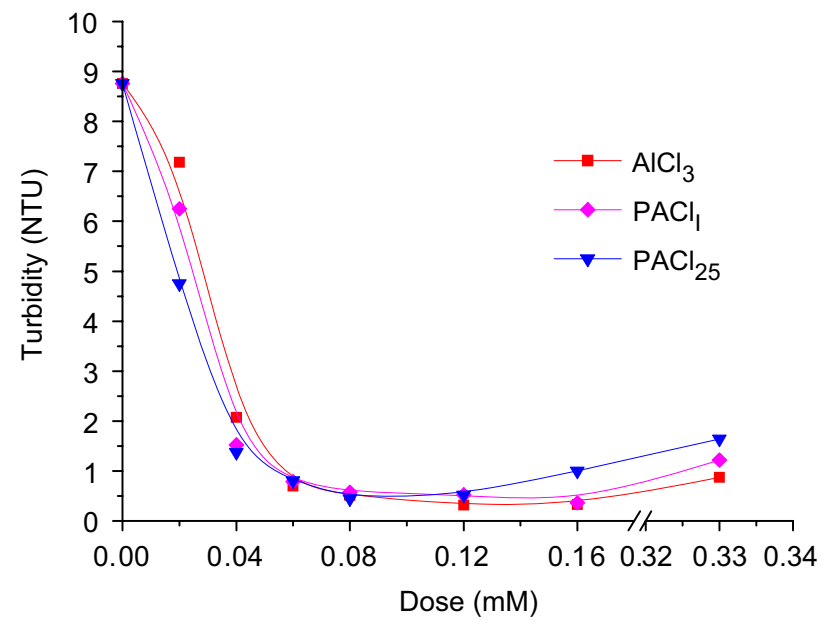

Fig. 3 - The comparison of PACls with various basicity for (a) DOC removal and (b) turbidity removal. 
PACls is correlated with DOC removal. $\mathrm{PACl}_{25}$ is the most efficient coagulant for DOC removal, followed by $\mathrm{PACl}_{\mathrm{I}}$ and $\mathrm{AlCl}_{3}$. The reason that $\mathrm{PACl}_{25}$ exhibited the best $\mathrm{DOC}$ removal could be due to the high neutralization ability of $\mathrm{Al}_{\mathrm{b}}$ species (Yan et al., 2007a).

At low dose $(0.02 \mathrm{mM})$, DOC removal performance was in the order of $\mathrm{PACl}_{25}>\mathrm{PACl}_{\mathrm{I}}>\mathrm{AlCl}_{3}$. When coagulant dose increased from 0.02 to $0.33 \mathrm{mM}$, DOC removal using $\mathrm{AlCl}_{3}$ was improved and finally $\mathrm{AlCl}_{3}$ became the most efficient coagulant in DOC removal. It needs to be noted that the solution $\mathrm{pH}$ dropped into the acidic range after the addition of $\mathrm{AlCl}_{3}$, while only slight $\mathrm{pH}$ changes were observed for the high $B$ value PACls (Yan et al., 2007a). The improved DOC removal by $\mathrm{AlCl}_{3}$ can be attributed to the drop in $\mathrm{pH}$ and the formation of $\mathrm{Al}_{\mathrm{b}}$ in-situ. However, $\mathrm{AlCl}_{3}$ coagulant is not an ideal choice for high-alkalinity waters because of highdosage requirement.

At low PACl dosage, the mechanism of turbidity removal is mainly through charge neutralization. The higher the content of $\mathrm{Al}_{\mathrm{b}}$ the greater the efficiency of turbidity removal. When doses are increased, particles may re-stabilize due to the formation of positively charged small flocs, and particularly when high-content $\mathrm{Al}_{\mathrm{b}}$ PACls are used (Yan et al., 2007a).

The results show that the pre-hydrolysis of $\mathrm{AlCl}_{3}$ could enhance the removal of DOC and turbidity for water with high alkalinity, at relatively low dosage. Also, it was found that the use of PACl could overcome the weakness of metal coagulant hydrolysis in high-alkalinity waters.

\subsection{Effect of coagulant aids on enhanced coagulation with $\mathrm{PACl}$}

Coagulant aids, such as organic polymers and activated silica, are commonly used to improve the performance of primary coagulant for turbidity and NOM removal. They can also be used with primary coagulants to prepare composite coagulants.

\subsubsection{Effects of polyelectrolytes on $\mathrm{PACl}$}

Cationic polymers are often used as coagulant aids to optimize coagulation and reduce the consumption of primary coagulant (Bolto et al., 1999; Edzwald and Tobiason, 1999; Chang et al., 2005). Two kinds of cationic polymers, PAM and PDADMAC, were selected to study the effects of cationic polymers on $\mathrm{PACl}_{\mathrm{I}}$ at a single dose of $0.06 \mathrm{mM}$ for the treatment of the Yellow River water.

As shown in Fig. 4, the addition of high molecular weight PAM (C1592, C1596) can enhance the efficiency of turbidity removal. However, low molecular weight PDADMAC has very little effect on turbidity removal. The effectiveness of these three organic polymers on turbidity removal enhancement is in the order of C1592>C1596>PDADMAC. It therefore suggests that molecular weight is more important for particle removal than charge density.

The effects of coagulant aids on NOM removal are not the same as turbidity removal. Among the three coagulant aids studied, PDADMAC is the most effective coagulant for NOM removal due to its highest positive charge density. Both $\mathrm{C} 1592$ and C1596 are high molecular weights coagulant aids and were found to be less effective in NOM removal.

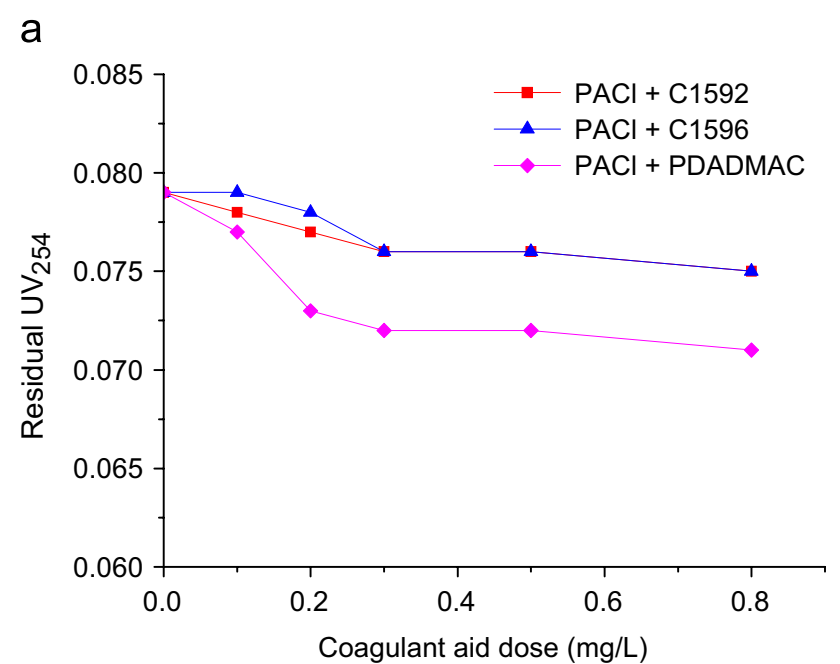

b

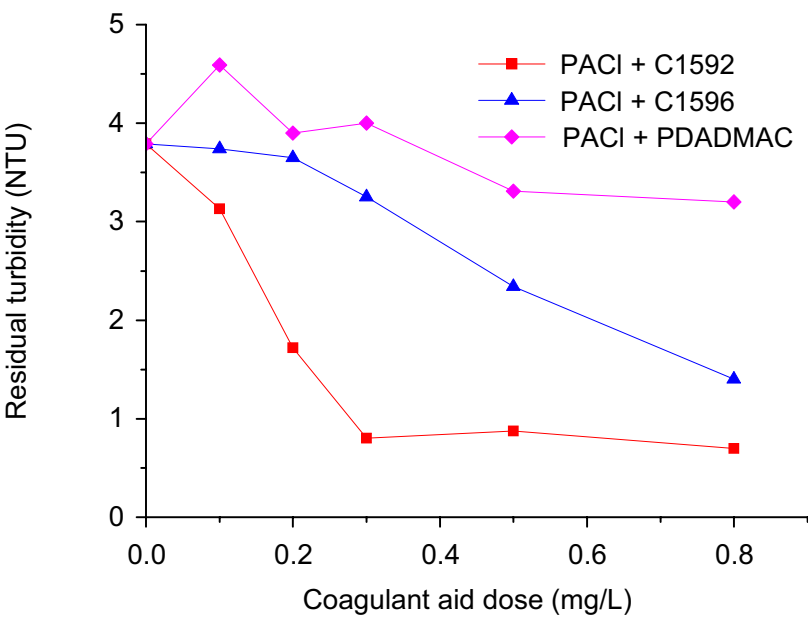

Fig. 4 - Effect of cationic polymers/coagulant aids on $\mathrm{PACl}$ at dose of $0.06 \mathrm{mM}$ for (a) $\mathrm{UV}_{\mathbf{2 5 4}}$ removal and (b) turbidity removal.

For turbidity removal, polymer bridging plays an important role, which is facilitated by high molecular weight polymers with relatively low charge density. For NOM removal, charge neutralization plays a dominant role. Generally, aqueous NOM is negatively charged and the coagulant demand for neutralizing the negative charge is much higher than that for neutralizing the charge of mineral particles. Therefore, PDADMAC with the highest positive charge was found to be the most efficient coagulant aid in terms of NOM removal (Chang et al., 2005; Yu et al., 2007). Due to the different mechanisms in mineral particles and OMr removal, it is difficult to simultaneously achieve optimal removal for both particles and NOM.

\subsubsection{Effects of activated silica on optimized coagulation}

$\mathrm{PACl}$ and activated silica, a form of PSi, can be used to prepare PASiC coagulant. PASiC may be prepared by prepolymerization of $\mathrm{Al}$ and silicate individually or by mixing $\mathrm{Al}$ salt and silicate prior to hydrolyzing and polymerizing together (Gao et al., 2002a, b).

The coagulation performance of PASiCs with various $\mathrm{Al} / \mathrm{Si}$ ratios has been evaluated in comparison with PACl by many 
a

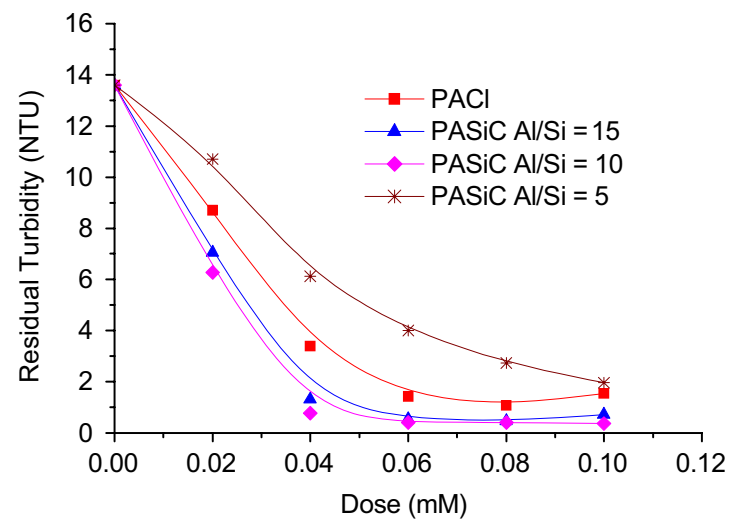

C

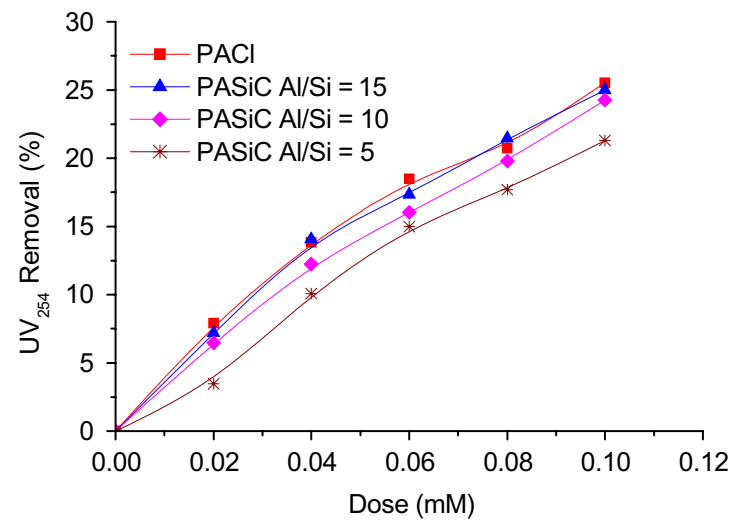

b

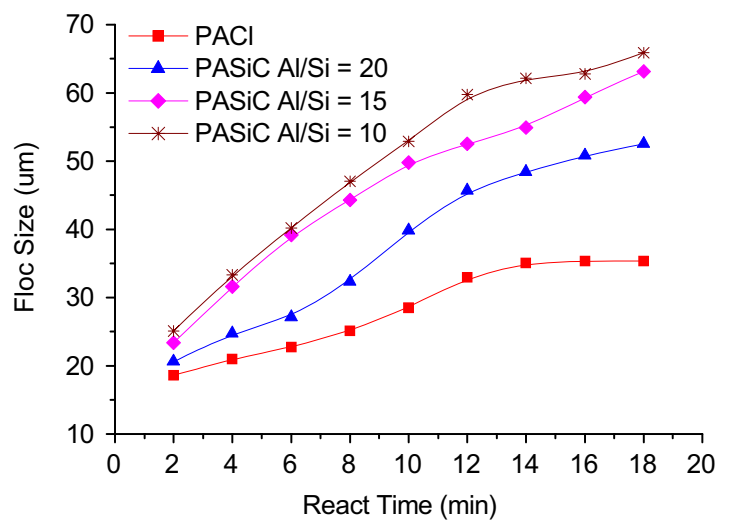

d

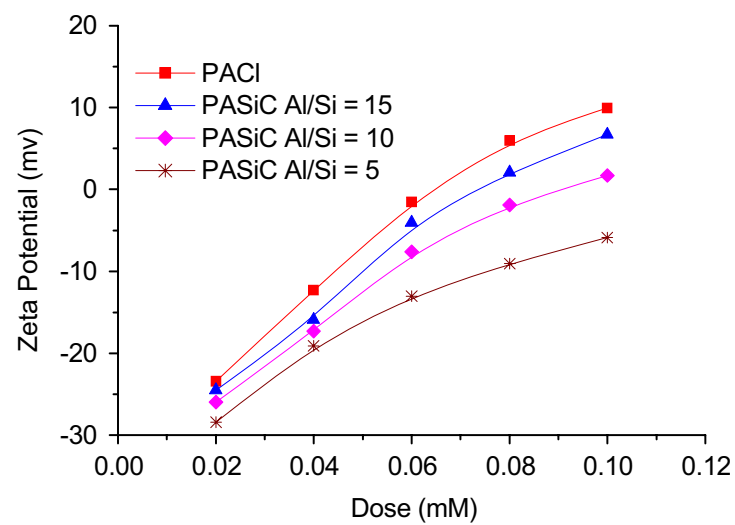

Fig. 5 - Comparison of coagulation performance with PASiCs and PACl.

researchers (Song, 1999; Gao et al., 2003; Shi, 2004; Liu, 2006). Results from using this coagulant on the Yellow River water are shown in Fig. 5.

It can be seen that PASiC coagulants are more effective than $\mathrm{PACl}$ coagulants in turbidity removal especially at lower doses when the ratio of $\mathrm{Al} / \mathrm{Si}$ in PASiC is not too low (Song, 1999; Gao et al., 2003). The PASiC coagulants are less effective than PACl coagulants in $\mathrm{UV}_{254}$ removal. It is indicated that incorporating low concentrations of PSi into polyaluminum salts can have both advantages and disadvantages on the coagulation performance of PACl (Arnold-Smith and Christie, 1992; Gao et al., 2002a, b). It has been found that PASiC coagulants have higher molecular weight than PACl coagulant, thus the bridge-formation capability of PASiC should be better than that of PACl. Consequently, flocs formed by PASiC developed more quickly and are larger than that formed by PACl. PSi, a negatively charged inorganic polymer, can decrease the positive charge of $\mathrm{PACl}$ when they were combined together. As the PSi portion of the coagulant increases, it gives more negative streaming current and zeta potential. The introduction of PSi into PACl could enhance the aggregating efficiency of $\mathrm{PACl}$, but the charge neutralization ability of PACl might be weakened.

\subsection{Novel highly efficient composite coagulant (HPAC)}

In view of the advantages and disadvantages of organic cationic polymers and activated silica, a new composite coagulant HPAC based on the modification of PACl with focusing on the efficient species of $\mathrm{Al}_{13}$, etc., and in combination of large composite polymer coagulation aids such as active silicates and PDADMAC was developed. These additives are able to enhance both the charge neutralization and bridging properties of PACl (Yan, 2006).

Coagulation using HPAC for northern China waters was compared with three commonly used coagulants $\mathrm{FeCl}_{3}, \mathrm{AlCl}_{3}$ and $\mathrm{PACl}$, in different seasons. The results for autumn Luan River water are shown here as an example in Fig. 6.

Fig. 6 shows that HPAC is the most efficient coagulant for both NOM and turbidity removal at low dosages. At a dosage of $0.04 \mathrm{mM}, 20 \%$ DOC removal can be achieved, which is higher than that by $\mathrm{AlCl}_{3}, \mathrm{FeCl}_{3}$ and $\mathrm{PACl}$. The percentage of TOC removal can reach the USEPA-enhanced coagulation requirements for the water with similar alkalinity and TOC levels (25\%). As the dosages increase, their differences become less. At high dosage, the adsorption-precipitation mechanism becomes dominant, and $\mathrm{FeCl}_{3}$ and $\mathrm{AlCl}_{3}$ efficiencies are greater than that of HPAC (Yan et al., 2006).

The results indicate that HPAC is more capable of removing DOC with high $\mathrm{UV}_{254}$ (high SUVA) at low coagulant dosage than other coagulants, and higher DOC removal by HPAC is mainly attributed to the additives besides PACl. The additives not only improve the charge neutralization and bridging properties of PACl but also adsorb some portions of NOM or complex with NOM to form co-precipitate. HPAC has been 


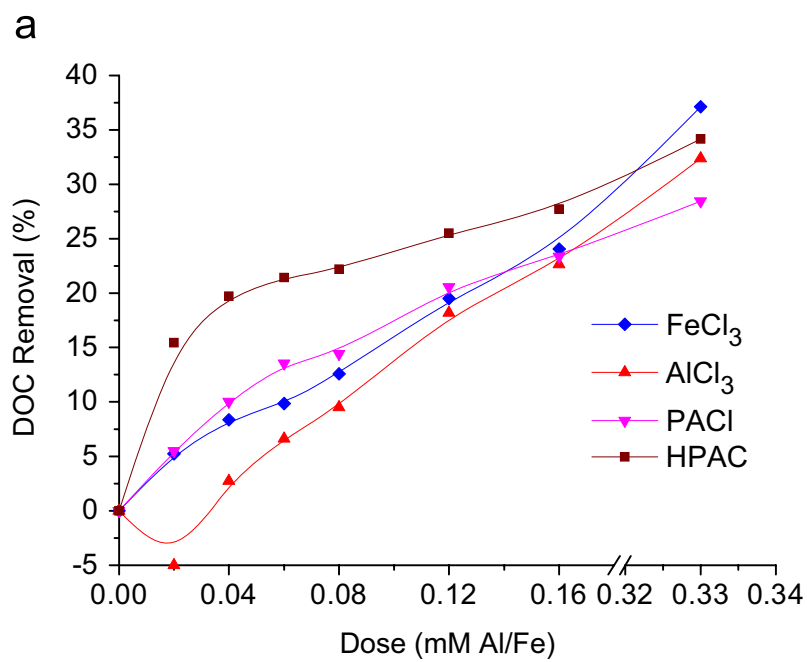

b

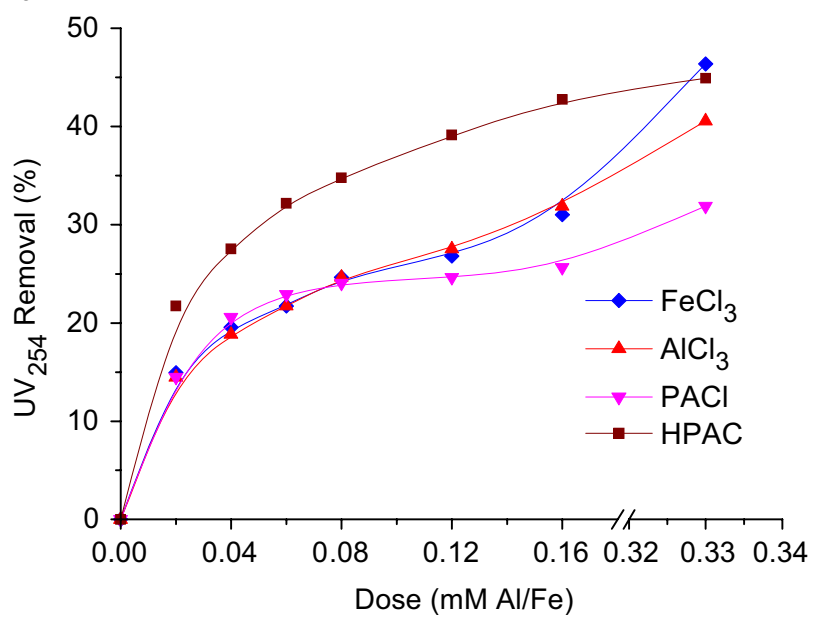

C

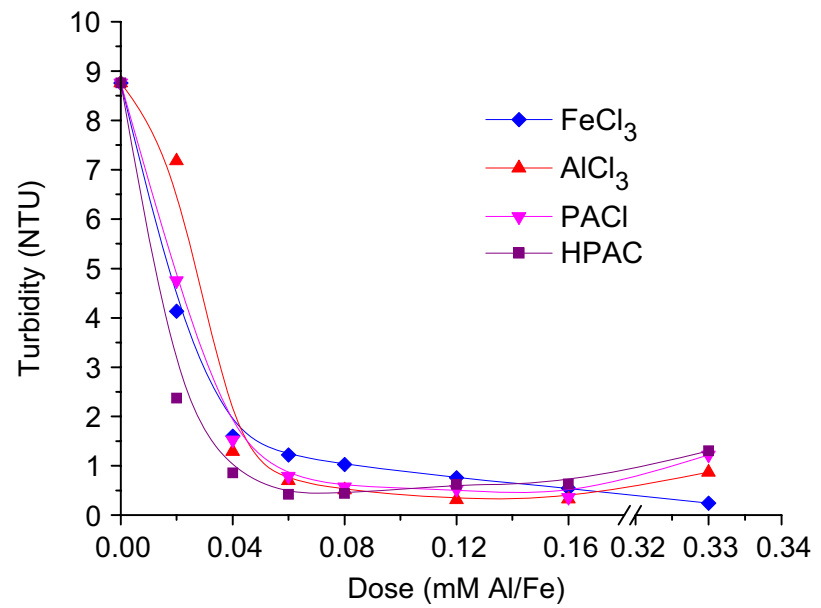

Fig. 6 - Comparison of HPAC and traditional coagulants for (a) DOC removal, (b) $\mathrm{UV}_{254}$ removal and (c) turbidity removal.

found to be more efficient in removing hydrophobic basic and neutral NOM, as well as high molecular weight NOM than $\mathrm{FeCl}_{3}$ (Yan et al., 2006).

Fig. 6 shows that HPAC is also more efficient in turbidity removal than $\mathrm{AlCl}_{3}$ and $\mathrm{PACl}$, and is as efficient as $\mathrm{FeCl}_{3}$. It is found that the flocs formed by HPAC have relatively larger dimension and lower fractal dimensions than those formed by $\mathrm{AlCl}_{3}$ and $\mathrm{PACl}$, and are much closer to those of $\mathrm{FeCl}_{3}$ (data not presented).

\subsection{Coagulation optimization: an integrated process}

As one of the most important steps in an integrated water treatment process, coagulation optimization should be conducted in considering its effect on other treatment steps.

\subsubsection{Effect of HPAC on solid/liquid separation}

Several researchers (Edzwald, 1983; O'Melia et al., 1987; Malley, 1988) found that removal of NOM following coagulation and flocculation was independent of the type of solid/ liquid separation process (flotation vs. sedimentation) with coagulants. However, the solid/liquid separation process is an important factor that affects the efficiency of HPAC for NOM removal.

When using HPAC as coagulant, TOC removal efficiency via flotation was found to be about 5\% higher than that by sedimentation. The TOC removal ratio of flotation-filtration increases up to about $9 \%$ higher than that of sedimentationfiltration. Flotation can remove hydrophobic DOC more efficiently because air bubbles have good affinity for hydrophobic DOC. Hydrophobic basic and neutral DOC can be almost completely removed by the flotation process, and the residual DOC concentration with molecular weight $>10 \mathrm{k}$ DOC is less than that by sedimentation (Yan et al., 2006).

The flocs formed by HPAC were smaller and less compact, which were not favorable for sedimentation, and the residual turbidities in the water following flotation and sedimentation were about 0.8 and $3.0 \mathrm{NTU}$, respectively. Although flotation is more efficient than sedimentation in turbidity removal, the residual turbidities after filtration are almost the same. However, the running period of sand filtration after sedimentation is half of that following flotation.

\subsubsection{Effect of pre-ozonation on coagulation with HPAC}

It was reported earlier that pre-ozonation can affect coagulation performance of $\mathrm{FeCl}_{3}$ (Yan et al., 2007b). Pre-ozonation acted as coagulation aid at a dose of $1.0 \mathrm{mg} / \mathrm{L} \mathrm{O}_{3}$ for turbidity and $\mathrm{UV}_{254}$ removal, while at a dose of $2.0 \mathrm{mg} / \mathrm{L} \mathrm{O}$, preozonation inhibited NOM removal (indicated as $\mathrm{UV}_{254}$ removal). The influence of pre-ozonation on the performance of HPAC for both turbidity and $\mathrm{UV}_{254}$ removal was not significant. This is in clear contrast to $\mathrm{FeCl}_{3}$.

Unlike $\mathrm{FeCl}_{3}, \mathrm{HPAC}$ can remove DOC through diverse mechanisms such as charge neutralization, adsorption and bridge formation. Hence, the removal of DOC by HPAC is less influenced by the pre-ozonation step. Even at high $\mathrm{O}_{3}$ dosage, the positively charged polymeric $\mathrm{Al}$ species together with the additives can efficiently neutralize and adsorb the ozonation products (e.g. organic acids) presented in ozonated water (Yan et al., 2007b).

\subsubsection{Effect of HPAC on filtration}

The effect of HPAC on filtration was studied by comparison with a composite coagulant prepared using $\mathrm{FeCl}_{3}, \mathrm{NaSiO}_{3}$ (prepared before dosing in 1:1) and coagulant aid PDADMAC 
$(0.15 \mathrm{mg} / \mathrm{L})$ in the pilot plant. Fig. 7 shows that the HPAC is not only more efficient in removal of NOM and turbidity than the traditional coagulant, but it can also achieve longer running period of sand filtration.

a

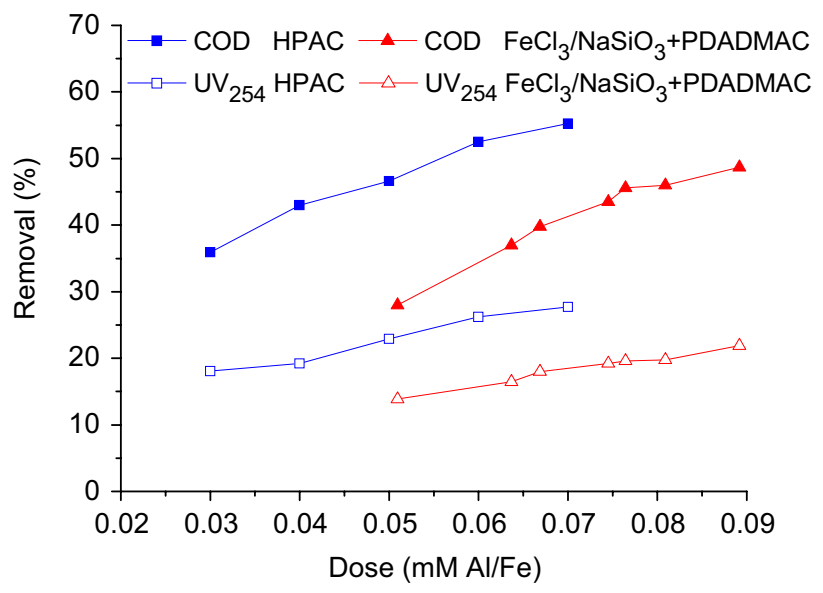

b

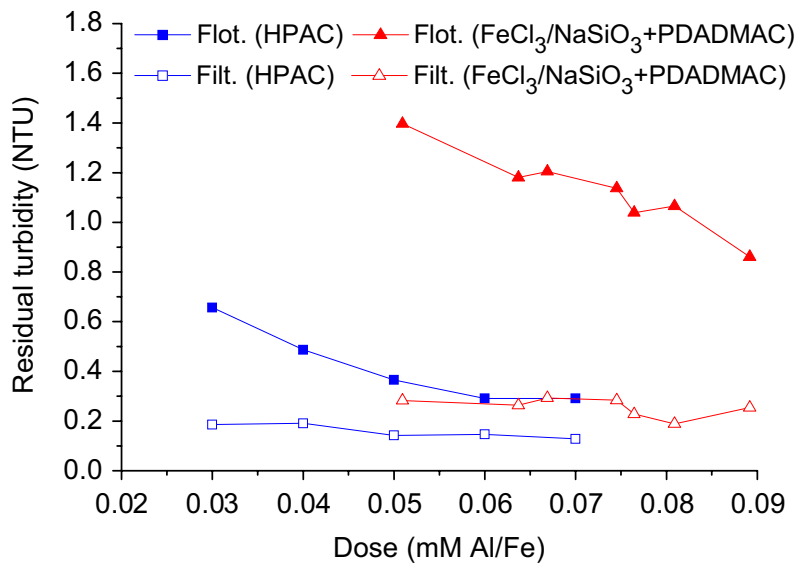

C

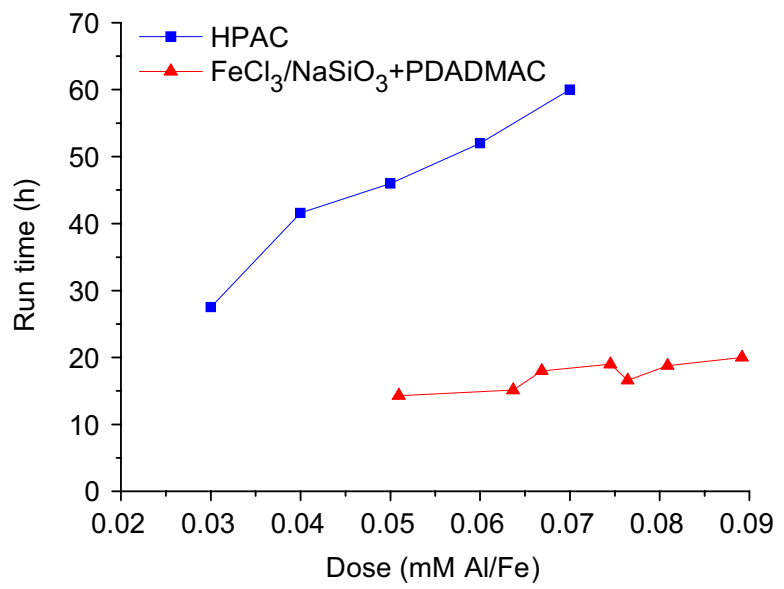

Fig. 7 - Effect of HPAC and traditional coagulants on filtration: (a) $U_{254}$ and $C O D_{M n}$ removal, (b) turbidity removal and (c) run time.
3.5.4. Residual Al of coagulation with coagulant HPAC The use of HPAC increased the concentrations of total Al to a much higher level in the water following flotation compared with that in raw water, but the dissolved $\mathrm{Al}$ in it only increased slightly, from 0.073 to $0.086 \mathrm{mg} / \mathrm{L}$. Most Al was in the form of flocs, which could be easily removed by sedimentation, flotation and sand filtration, and the residual dissolved $\mathrm{Al}$ can be lowered to $0.064 \mathrm{mg} / \mathrm{L}$. The residual $\mathrm{Al}$ was further decreased to $0.043 \mathrm{mg} / \mathrm{L}$ with the removal of NOM in the subsequent mid-ozonation and GAC filtration process, lower than the limitation of Al content in Standards for Drinking Water Quality of China (GB 5749-2006), 0.2 mg/L (Yan et al., 2007c).

\section{Conclusion}

In this paper, a study conducted on enhanced coagulation of high-alkalinity and micro-polluted water was reported. The main conclusions drawn are as follows:

(1) For the traditional coagulants, alum and ferric salts, optimum $\mathrm{pH}$ condition for NOM removal is in the acidic region $(\mathrm{pH}<6.0)$. Using pre-hydrolyzed polyaluminum coagulants, efficient NOM removal can be achieved for raw water with high alkalinity at a higher $\mathrm{pH}$. Preformed medium polymers $\left(\mathrm{Al}_{\mathrm{b}}\right)$ are accountable for the effectiveness of polyaluminum coagulants in terms of NOM removal.

(2) Organic cationic polymers and activated silica are efficient coagulation aids to improve the coagulation performance of PACl. Organic cationic polymers can enhance the neutralization ability of $\mathrm{PACl}$, and activated silica can enhance the bridging ability of PACl.

(3) A new composite coagulant (HPAC) was developed especially for high alkalinity and micro-polluted water, and is highly efficient in NOM and turbidity removal. Particles and NOM were removed synergistically with HPAC as coagulant by sequential treatment of different processes including pre-ozonation, coagulation, flotation and sand filtration. The residual $\mathrm{Al}$ is relatively low.

(4) Coagulant optimization such as HPAC application can be considered as an alternative option to acidifying the raw water and applying increased doses of hydrolyzing coagulants to enhance NOM removal from high-alkalinity and micro-polluted waters.

\section{Acknowledgments}

The authors are very grateful for the kind help from the people of the Tianjin water treatment plant who provided full supports to this research. The kind suggestions from the anonymous reviewers are greatly acknowledged. This research is funded by the NSF of China under 50578155, 50621804 and 20477054, The National Key Technology R\&D Program of China under 2006BAD01B03 and 2006BAD01B09, and national 863 projects under 2002AA126040. This project was supported by China Postdoctoral Science Foundation also. 
APHA, AWWA, WEF, 1995. Standard Methods for the Examination of Water and Wastewater, 19th ed. American Public Health Association, Washington, DC, pp. 253-258.

Arnold-Smith, A.K., Christie, R.M., 1992. Polyaluminum silicate sulfate-a new coagulant for potable and wastewater treatment. In: Klute, R., Hahn, H.H. (Eds.), Chemical Water and Wastewater Treatment II. Proceedings of the Fifth Gothenburg Symposium, Nice, France. Springer, Berlin, pp. 203-219.

Bolto, B., Abbt-Braun, G., Dixon, D., Eldridge, R., Frimmel, F., Hesse, S., King, S., Toifl, M., 1999. Experimental evaluation of cationic polyelectrolytes for removing natural organic matter from water. Water Sci. Technol. 40 (9), 71-79.

Carlson, K., Via, S., Bellamy, B., Carlson, M., 2000. Secondary effects of enhanced coagulation and softening. J. Am. Water Works Assoc. 92 (6), 63-75.

Chang, E.E., Chiang, P.C., Tang, W.Y., Chao, S.H., Hsing, H.J., 2005. Effects of polyelectrolytes on reduction of model compounds via coagulation. Chemosphere 58 (5), 1141-1150.

Crozes, G.P., White, P., Marshall, M., 1995. Enhanced coagulation: its effect on NOM removal and chemical costs. J. Am. Water Works Assoc. 87 (1), 78-89.

Edzwald, J.K., 1983. Coagulation-sedimentation-filtration processes for removing organic substances of ran drinking water. In: Berger, B.B. (Ed.), Control of Organic Substances in Water and Wastewater. USEPA, EPA-600/8-83-011, Washington, DC.

Edzwald, J.K., 1993. Coagulation in drinking water treatment: particles, organics and coagulants. Water Sci. Technol. 27 (11), 21-35.

Edzwald, J.K., Tobiason, J.E., 1999. Enhanced coagulation: US requirements and a broad review. Water Sci. Technol. 40 (9), 67-70.

Gao, B.Y., Hahn, H.H., Hoffmann, E., 2002a. Evaluation of aluminum-silicate polymer composite as a coagulant for water treatment. Water Res. 36 (14), 3573-3581.

Gao, B.Y., Yue, Q.Y., Wang, B.J., 2002b. The chemical species distribution and transformation of polyaluminum silicate chloride coagulant. Chemosphere 46 (6), 809-813.

Gao, B.Y., Yue, Q.Y., Wang, B.J., Chu, Y.B., 2003. Poly-aluminumsilicate-chloride (PASiC) - a new type of composite inorganic polymer coagulant. Colloids Surf. A 229, 121-127.

Liu, L.L., 2006. Study on species distribution of aluminum and properties of polyaluminum silicate chloride. Dissertation for MS, Shandong University, Shandong (in Chinese).

Malley Jr., J.P., 1988. A fundamental study of dissolved air flotation for treatment of low turbidity waters containing natural organic matter. Dissertation for Ph.D., Department of Civil Engineering, University of Massachusetts, Amherst, pp. 35-60.

O’Melia, C.R., Yao, K., Gray, K., Tobiason, J.E., 1987. Raw water quality, coagulant selection, and solid-liquid separation. In: Presented at the 1987 AWWA Annual Conference Seminar on Influence of Coagulation on the Selection, Operation, and Performance of Water Treatment facilities, Kansas City, MO, June 14.

Shi, J., 2004. Study on the preparation and application of the new inorganic polymer flocculant. Dissertation for Ph.D., China University of Geosciences, Beijing (in Chinese).

Song, Y.H., 1999. Study and application on new high efficient floculant polyaluminum silicate chloride. Dissertation for Ph.D., Research Center for Eco-Environmental Sciences, Chinese Academy of Sciences, Beijing (in Chinese).

USEPA, 1998. Enhanced Coagulation and Enhanced Precipitative Softening Guidance Manual. EPA, Office of Water and Drinking Ground Water, Washington, DC, pp. 20-50.

Wang, D.S., Tang, H.X., 2001. Modified inorganic polymer flocculant-PFSi: its preparation, characterization and coagulation behavior. Water Res. 35 (14), 3418-3428.

Wang, D.S., Sun, W., Xu, Y., Tang, H.X., Gregory, J., 2004. Speciation stability of inorganic polymer flocculant-PACl. Colloids Surf. A 243, 1-10.

Yan, M.Q., 2006. Enhanced Coagulation and Treatment System Optimization for High Alkalinity and Micro-polluted Water. Dissertation for Ph.D., Research Center for Eco-Environmental Sciences, Chinese Academy of Sciences, Beijing (in Chinese).

Yan, M.Q., Wang, D.S., Qu, J.H., He, W.J., Chow, C.W.K., 2007a. Relative importance of hydrolyzed Al(III) species (Ala, Alb and Alc) during coagulation with polyaluminum chloride: a case study with the typical micro-polluted source waters. J. Colloid Interface Sci. 316 (2), 482-489.

Yan, M.Q., Wang, D.S., Shi, B.Y., Wang, M., Yan, Y., 2007b. Effect of pre-ozonation on optimized coagulation of a typical NorthChina source water. Chemosphere 69 (11), 1695-1702.

Yan, M.Q., Wang, D.S., Shi, B.Y., Wei, Q.S., Qu, J.H., Tang, H.X., 2007c. Transformation of particles, NOMs and elements in a Chinese pilot-scale drinking water treatment processes. J. Environ. Sci. China 19 (3), 271-277.

Yan, M.Q., Wang, D.S., You, S.J., Qu, J.H., Tang, H.X., 2006. Enhanced coagulation in a typical North-China water plant. Water Res. 40 (19), 3621-3627.

Yu, J.F., Wang, D.S., Yan, M.Q., Ge, X.P., 2007. Optimized coagulation of high alkalinity low temperature and particle water $\mathrm{pH}$ adjustment and polyelectrolytes as coagulant aids. Environ. Monit. Assess. 131, 377-386. 